\title{
Water retention and shrinkage curves of weathered pyroclastic soil
}

\author{
Ana Sofia Dias ${ }^{1,2,3^{*}}$, Abhijith Kamath $^{4}$, Marianna Pirone ${ }^{1}$, and Gianfranco Urciuoli $^{1}$ \\ ${ }^{1}$ DICEA, University of Naples Federico II, Via Claudio 21, 80125 Napoli, Italy \\ ${ }^{2}$ AMAP, INRA, IRD, CNRS, CIRAD, University of Montpellier, 34398 Montpellier Cedex 5, France \\ ${ }^{3}$ Department of Engineering, Durham University, Lower Mountjoy, DH1 3LE Durham, UK \\ ${ }^{4}$ Faculty of Civil engineering and Geosciences, TU Delft, Gebouw 23, Stevinweg 1, 2628 CN Delft, The Netherlands
}

\begin{abstract}
The modelling of the triggering mechanism of rainfall-induced landslides in slopes covered by pyroclastic soil (as the area surrounding Mount Vesuvius in Campania, Italy) requires the hydraulic characterization of soil in unsaturated conditions in order to analyse the slope response to rainfalls. In previous studies carried out on Campanian pyroclastic soils, the volumetric soil changes due to suction changes have been disregarded, being them negligible in soils characterized by low plasticity and low clay contents. However, a more accurate determination of the water retention curve (WRC) in terms of volumetric water content requires a correct estimation of the total soil volume, which is affected by the soil stress-state. The proper approach would require the estimation of both WRC in terms of gravimetric water content and the shrinkage curve (SC). In the present study, a relation between void ratio and suction was determined for a pyroclastic soil sampled at Mount Faito in Southern Italy. Therefore, a correction of the volumetric water content was carried out resulting in updated water retention curves. Here, the matric suction was the only factor affecting the stress-state of the soil.
\end{abstract}

\section{Introduction}

In the Campania region (Southern Italy), shallow landslides triggered by intense rainfall occur in sloping pyroclastic deposits generated by explosive eruptions of Mount Vesuvius [1]. Efforts have been made to characterize the hydraulic properties of such soils [2-4]. However, previous studies on the Campanian pyroclastic soil assumed that the volume changes due to drying and wetting are negligible, as usually occurs when contents of fines and plasticity are low [2-7]. Picarelli et al. [8] present the only study on the volume change effect on the water retention curve (WRC) of the Neapolitan pozzolana.

Water content variations in the soil are linked to variations of matric suction which in turn changes the effective stress-state of the soil. The suction increase leads to a decrease of the soil volume $[9,10]$ that must be taken into account in the estimation of the water content, especially when it is defined in terms of volume of water per unit volume of soil, i.e. the volumetric water content.

Hence, the WRC depends on the stress-state of the soil. Constitutive relations between water content, void ratio and stress-state have been proposed for the characterization of deformable soils $[9,10]$. Additionally, cyclic drying and wetting leads to accumulation of elastoplastic deformations in the soil that affect WRCs [10,11].
Three quantities need to be monitored during evaporation and/or imbibition of deformable soil for their hydraulic properties determination: (i) gravimetric water content, (ii) matric suction, and (iii) volume variations [13], when soil is not mechanically loaded. The relation between the first and the second (i and ii) is the WRC and the relation between the first and the third (i and iii) is the shrinkage curve (SC).

In the present work, the WRC is assessed in terms of gravimetric water content and the changes of void ratio caused by changes of water content are presented.

\section{Methods and materials}

\subsection{Soil physical properties}

Pyroclastic soil samples collected approximately at a depth of $2 \mathrm{~m}$ in Mount Faito (Campania, Italy) were used in the present study. Undisturbed soil specimens were taken horizontally on natural and artificial vertical fronts and then used for the physical and hydraulic characterization described in the present paper.

This soil originates from a volcanic eruption older than the eruption of $79 \mathrm{AD}$ and is affected by weathering. The soil consists of sandy silt with $2-5 \%$ of clay, $40-65 \%$ of silt, $25-50 \%$ of sand and $3 \%$ of gravel (pumices) [4]. The liquid limit was 58\% and the plasticity index was $8 \%$, therefore this soil is fine and

Corresponding author: ana.s.dias@ durham.ac.uk 
characterized by low plasticity [4]. The soil presented a specific gravity of $2.656 \pm 0.017$ (dimensionless) and a porosity of $0.722 \pm 0.267$ [4].

\subsection{Soil hydraulic properties}

The WRCs of the investigated soil were determined on cylindrical soil specimens with a diameter of $72 \mathrm{~mm}$ and a length of $60 \mathrm{~mm}$ by using the ku-pf apparatus (ku-pf MP10 by UGT). The specimens, installed vertically, were contained in metallic sleeves that restrain the soil from expanding and prevent evaporation through the lateral sides. The apparatus consists of a star-shaped sampler changer, which can manage up to ten samples. The matric suction is measured at $15 \mathrm{~mm}$ and $45 \mathrm{~mm}$ from the top of the specimen by two mini-tensiometers installed horizontally on the external side of the sleeves. These mini-tensiometers allow measurements with a resolution of $0.01 \mathrm{kPa}$ between 0 and $80 \mathrm{kPa}$. Each pair of pressure sensors is connected to a conditioning unit arranged upon each sample holder. The star-shaped changer periodically places each sample holder upon a precision balance (resolution of $0.01 \mathrm{~g}$ ) and total soil water storage changes are determined from weight measurements.

The soil specimens were saturated inside a permeameter by flushing water at low pressure through the soil and were successively placed in each of the arms of the ku-pf apparatus. The water was allowed to evaporate from the top of the specimen while the bottom was sealed with Parafilm $\mathrm{M}$ and a cap with a tight $\mathrm{O}-$ ring. The weight and suction values were measured every 10 minutes and the entire test lasted about 7 days. At the end of the test, water content and porosity were obtained by the gravimetric method (scale precision of $0.01 \mathrm{~g})$.

The main drying path of the WRC was obtained by estimating the gravimetric water content from the variations of the sample-weight recorded by the ku-pf apparatus. The matric suction was assumed as the average of the values measured by both tensiometers.

In this study, the van Genuchten WRC model [14] was adopted to fit experimental data and to obtain the WRC accounting for the variations in void ratio. The model can be expressed by Equation 1, where $n$ and $a$ are fitting parameters, $w$ is the gravimetric water content, $s$ is the matric suction, $e$ is the soil void ratio and $G_{s}$ is the specific gravity of the solid particles. The fitting parameters were obtained by the least-square method.

$$
w=e / G_{s}\left[1+(s / a)^{1 /(1-n)}\right]^{-n}
$$

\subsection{Void ratio and matric suction measurements}

The SC was obtained by coupling the values of gravimetric water content and void ratio measured on soil specimens in natural conditions as collected from field. The SC is linear for water contents above the shrinkage limit below which the void ratio becomes constant $[11,13]$. Part of the data set was complemented by measurements of matric suction in order to be able to represent the data on the water retention plan.
Different soil samples $(60 \times 60 \times 20 \mathrm{~mm})$ were placed in the chamber of a direct shear test equipment for testing in unsaturated conditions [13]. However, they are used here for another purpose. Axis translation technique was employed to measure matric suction at natural conditions, as undisturbed samples preserved the moisture from field. Matric suction was measured by raising the air pressure in the chamber to $100 \mathrm{kPa}$. The water pressure valve was closed throughout in order to prevent water flow and to allow the water pressure to be measured. The initial volume of the specimen was measured before installing it in the shear test apparatus. The initial water content was obtained by the gravimetric method at the end of the test after removing the specimen from the equipment (scale precision of $0.01 \mathrm{~g}$ ).

\section{Results and discussion}

\subsection{Soil water retention curve}

Three specimens, named $\mathrm{A}, \mathrm{B}$ and $\mathrm{C}$, were used to obtain the WRC along the main dry path. Initial suction, volumetric and gravimetric water content, and void ratio and porosity are presented in Table 1. The WRCs in terms of gravimetric water content measured on these specimens by the ku-pf are presented in Figure 1, i.e. mean values of matric suction measured by the two tensiometers and respective gravimetric water content derived from recorded weight variations of the sample.

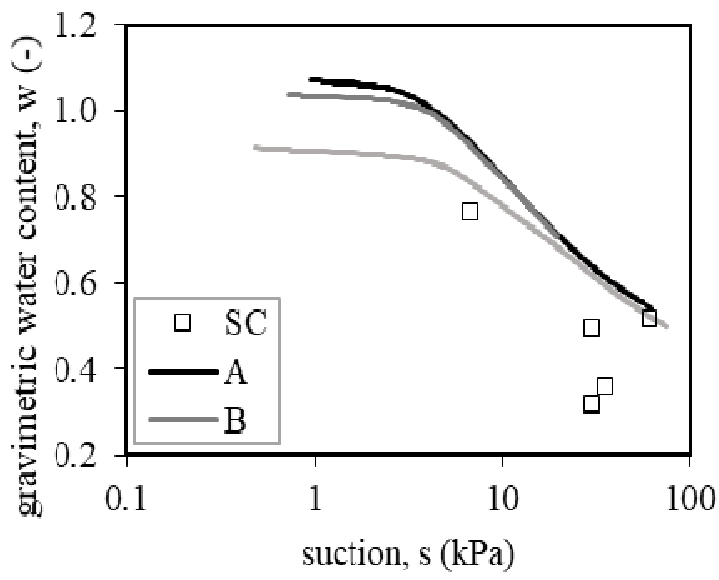

Fig. 1. WRCs measured by the ku-pf apparatus on specimens $\mathrm{A}, \mathrm{B}$ and $\mathrm{C}$ (continuous lines) and data points (square symbols) determined on samples used for identifying the SC.

The water content for low suction values varies among the specimens depending on the amount of air that remains entrapped during the saturation phase. Variability is also due to different values of porosity: the specimen $\mathrm{C}$ presents the lowest porosity and the lowest water content close to saturation among the three investigated specimens. However, all the curves present similar air-entry value and slope. These curves have been reported by Dias [4] in terms of volumetric water content assuming no volume change during the drying process. 
Table 1. Matric suction (s), void ratio (e), porosity (n), gravimetric water content $(\mathrm{w})$, and volumetric water content $(\theta)$ of each sample used to obtain the shrinkage curve (SC) and the water retention curve (WRC).

\begin{tabular}{|c|c|c|c|c|c|c|}
\hline Test & Spec. & $\begin{array}{c}\mathrm{s} \\
(\mathrm{kPa})\end{array}$ & $\mathrm{e} \mathrm{(-)}$ & $\mathrm{n}(-)$ & $\mathrm{w} \mathrm{(-)}$ & $\theta(-)$ \\
\hline WRC & $\mathrm{A}$ & 0.94 & 3.113 & 0.757 & 1.071 & 0.658 \\
\hline WRC & B & 0.72 & 2.962 & 0.748 & 1.037 & 0.661 \\
\hline WRC & $\mathrm{C}$ & 0.49 & 2.681 & 0.728 & 0.914 & 0.628 \\
\hline SC & 1 & 61.7 & 2.006 & 0.667 & 0.516 & 0.434 \\
\hline SC & 2 & 6.8 & 2.148 & 0.682 & 0.763 & 0.613 \\
\hline SC & 3 & 30.0 & 1.580 & 0.612 & 0.495 & 0.485 \\
\hline SC & 4 & 35.1 & 1.100 & 0.524 & 0.359 & 0.432 \\
\hline SC & 5 & 30.3 & 1.012 & 0.503 & 0.318 & 0.400 \\
\hline SC & 6 & - & 1.996 & 0.666 & 0.771 & 0.650 \\
\hline SC & 7 & - & 1.652 & 0.623 & 0.585 & 0.558 \\
\hline SC & 8 & - & 2.377 & 0.704 & 0.843 & 0.631 \\
\hline SC & 9 & - & 1.999 & 0.667 & 0.693 & 0.584 \\
\hline SC & 10 & - & 1.996 & 0.666 & 0.771 & 0.650 \\
\hline SC & 11 & - & 1.652 & 0.623 & 0.585 & 0.558 \\
\hline SC & 12 & - & 2.377 & 0.704 & 0.843 & 0.631 \\
\hline SC & 13 & - & 1.999 & 0.667 & 0.693 & 0.584 \\
\hline SC & 14 & - & 2.166 & 0.684 & 0.800 & 0.638 \\
\hline SC & 15 & - & 2.102 & 0.678 & 0.744 & 0.606 \\
\hline
\end{tabular}

\subsection{Soil shrinkage curve}

Fifteen specimens, numbered from 1 to 15 , were used to obtain the shrinkage curve (SC). As seen in Table 1, these specimens present a lower water content than values determined at the initial phase of the test on specimens used to obtain the WRCs. Firstly, this occurs because the specimens have a lower porosity than the specimens used to determine the WRCs. Then, these specimens were tested in natural conditions and each of them experienced different hydraulic hysteretic loops.

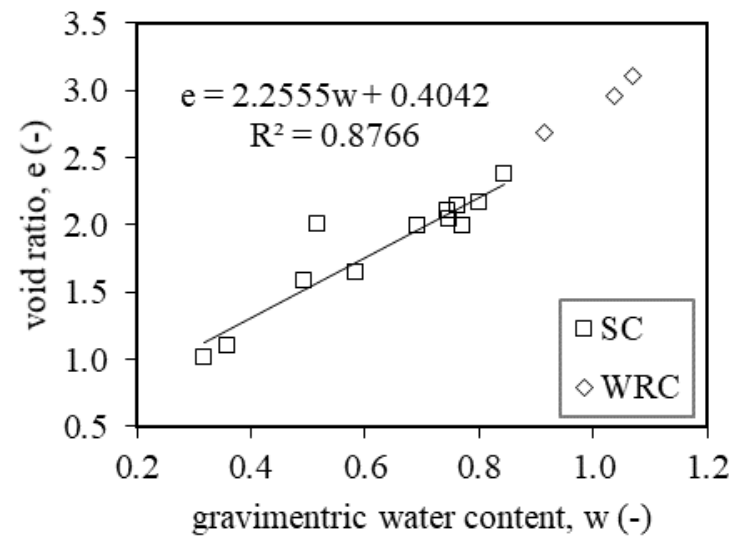

Fig. 2. Data (square symbol) to detect the shrinkage curve (SC) (line) and data correspondent to the initial conditions of the samples used to determine the WRCs along dry paths (rhombus symbol).
In Figure 2, a clear decrease in the void ratio with decreasing gravimetric water content can be observed. A linear regression fits experimental data well with a high determination coefficient $\left(\mathrm{R}^{2}\right)$. This observation can be explained by the fact that the soil void ratio tends to decrease with increasing suction as a consequence of the associated effective stress increase in the soil $[9,10,12$, $16,17]$. However, this curve is incomplete because the void ratio decreases up to a threshold correspondent to the shrinkage limit characteristic of each soil, which cannot be observed in Figure 2

Note that there is coherency among data sets (SC and WRC), as the initial conditions of the specimens tested to obtain WRCs, represented in Figure 2, align with the linear regression. In fact, the specimens used to obtain the WRC presented a higher water content and porosity being them subjected to a lower matric suction, hence a lower effective stress.

The slope of the linear regression presented in Figure 2 was used to estimate the variations in void ratio during the drying test performed on the specimens A, B, C. The estimation was made using Equation 2, where $e$ is the current void ratio, $e_{\mathrm{i}}$ is the initial void ratio (close to saturation), $w$ is the gravimetric water content and $w_{\mathrm{i}}$ is the initial water content correspondent to $e_{\mathrm{i}}$. The void ratio cannot exceed the initial void ratio $e_{\mathrm{i}}$ because the specimen is horizontally confined, and the soil is subjected to evaporation.

$$
e=e_{\mathrm{i}}+2.2555 \cdot\left(w-w_{\mathrm{i}}\right)
$$

\subsection{Effect of soil volume change on the-WRC}

The WRCs determined on specimens A, B, and C have been represented in terms of volumetric water content in Figure 3. In particular, the curves estimated accounting for the soil volume change calculated using Equation 2 (continuous lines) and those assuming no-volume change (dotted lines) are compared.

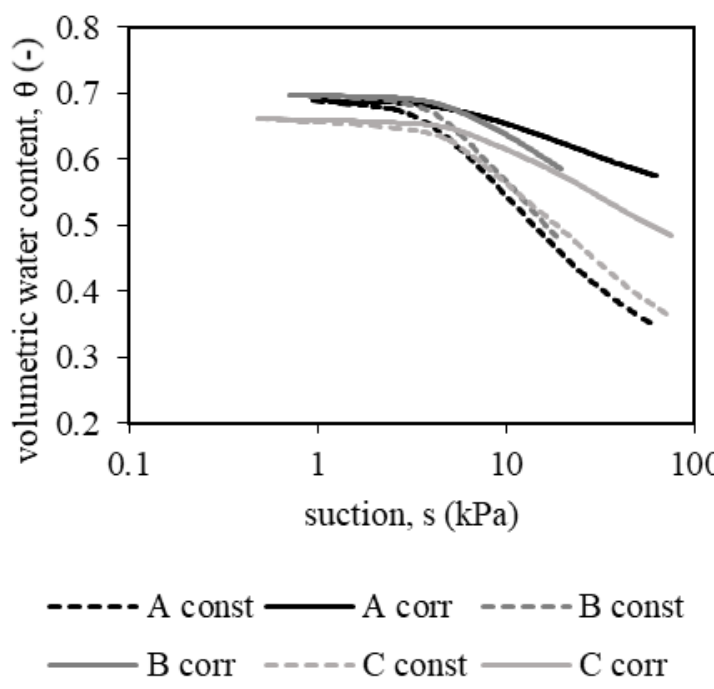

Fig. 3. Comparison of the WRCs in terms of volumetric water content when the soil volume is considered constant (const) (dotted lines) and when it is corrected by using the shrinkage curve (corr) (continuous lines). 
The decrease in volumetric water content when the volume of the specimen is assumed constant (const) is more significant than when the void ratio correction is adopted (corr). The mismatch appears greater beyond the air-entry value.

The van Genuchten model (Equation 1) was chosen to fit the WRCs in terms of gravimetric water content. Coefficients of determination for each specimen resulted close to 1 (Table 2). The parameter $a$, associated to the air-entry value, varied between 8.37 and $10.86 \mathrm{kPa}$ and the parameter $n$ varied between 0.244 and 0.268 . These results are comparable to fitting parameters obtained for similar pyroclastic soil reported by Nicotera et al. [3].

Table 2. Fitting parameters of the van Genuchten model (Equation 1) and determination coefficient of fitting $\left(\mathrm{R}^{2}\right)$ for each specimen.

\begin{tabular}{|c|c|c|c|c|}
\hline soil & A & B & C & average \\
\hline$a(\mathrm{kPa})$ & 8.37 & 12.32 & 10.86 & 10.52 \\
\hline$n(-)$ & 0.268 & 0.361 & 0.244 & 0.291 \\
\hline $\mathrm{R}^{2}$ & 0.979 & 0.990 & 0.995 & - \\
\hline
\end{tabular}

In Figure 4, the average WRC (continuous red line) is presented, where the parameters $a$ and $n$ were assigned equal to the average values reported in Table 2, and the initial gravimetric water content was assumed to be the average of the values determined on the three specimens $\mathrm{A}, \mathrm{B}$ and $\mathrm{C}$ that resulted close to saturation, that is 1.007 . The curve, thus modelled, is intended to capture the average main drying branch of WRC of this soil. Figure 4 also shows the WRCs determined on specimens A, B, $\mathrm{C}$ (black and grey lines) for both conditions, accounting for volume change and assuming constant volume, and the SC experimental data points (square symbols).

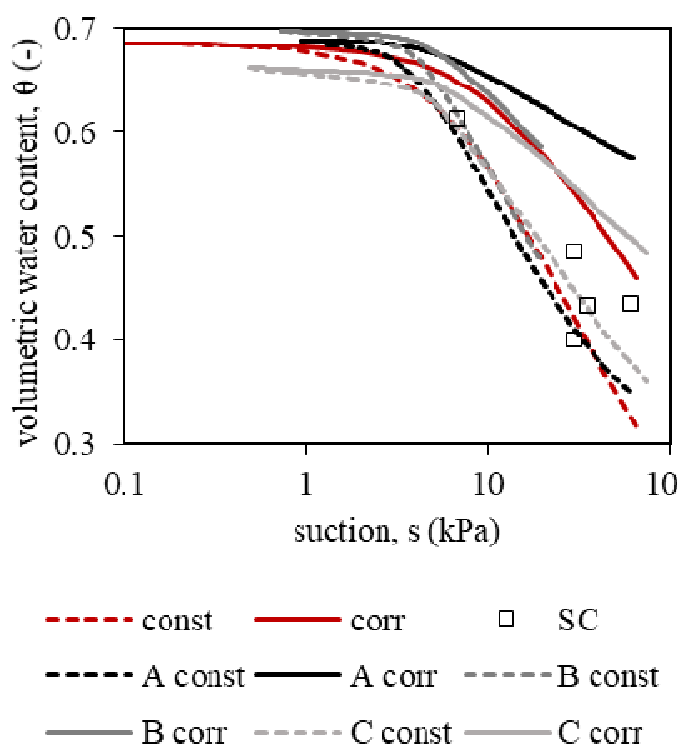

Fig. 4. Comparison of the SC data points (square symbols) with the WRCs in terms of volumetric water content when the volume is considered constant (const) (dotted line) and when the volume is corrected with the shrinkage curve (corr) (continuous lines).
Each couple of measured suction and void ratio, used for the SC construction (specimens 1 to 5), was determined on specimens collected not exactly at the same depth and that have experienced different hydraulic hysteretic loops at field. Therefore, these data points belong to scanning paths that depend on the hydraulic history of each specimen.

The WRCs that assume constant soil volume (const, dotted lines) present lower suctions than the ones observed in the specimens 1 to 5 (SC). On the other hand, the WRCs that account for the volume change (corr, full lines) represent suctions that are higher than the ones of the SC points. As the SC points belong to scanning paths, accounting for volume changes provides a more realistic representation of WRCs.

If soil volume variations are not accounted, the airentry value (AEV) determined on WRCs in terms of volumetric or gravimetric water content is the same, ranging between 3.5 and $5 \mathrm{kPa}$. The $\mathrm{AEV}$ results higher on WRCs in terms of volumetric water content when soil volume variations are taken into account, ranging between 4.5 and $6 \mathrm{kPa}$. This feature has implications on the modelling of drying soil as the desaturation, when the volume is corrected, occurs later on, i.e. suction reaches higher values before air starts entering the soil pores.

Hence, the void ratio of low plasticity pyroclastic soil was proven to depend on the soil water content variation. This dependency clearly affects the WRC estimations in terms of volumetric water content. However, the importance of such change is not known and more research is needed on the effect of the stress-state on the hydraulic properties of pyroclastic soil and on the water infiltration simulations.

\section{Conclusion}

A relationship was found between void ratio and gravimetric water content (shrinkage curve) for sandy silt pyroclastic soils with low plasticity. The initial soil void ratio of all the tested specimens decreased with decreasing natural water content.

The WRCs determined along main drying paths on three specimens of pyroclastic soil have been updated accounting for the soil volume change. The slope of the curves results smaller as a consequence of the reduction of void ratio with decreasing gravimetric water content. The suction and volumetric water content determined on the specimens in natural conditions resulted properly placed in the hysteretic domain on water retention plane, when the main drying WRC was estimated accounting for soil volume change predicted by SC.

The soil void ratio was shown to depend on the water content, it reduces upon drying. Summing up, more investigation on the effect of stress state on the soil hydraulic properties of pyroclastic soil is required.

\section{Acknowledgements}

The authors wish to acknowledge the support of the European Commission via the Marie Skłodowska-Curie Innovative 
Training Networks (ITN-ETN) project TERRE 'Training Engineers and Researchers to Rethink geotechnical Engineering for a low carbon future' (H2020-MSCA-ITN2015-675762).

\section{References}

1. A. Santo, G. Di Crescenzo, G. Forte, R. Papa, M. Pirone, G. Urciuoli, Landslides, 15, 1 (2018)

2. M. Pirone, R. Papa, M. V. Nicotera, G. Urciuoli. Procedia Engineering 158, (2016)

3. M. V. Nicotera, R. Papa, G. Urciuoli, Geotech. Test. J. 33, 4 (2010)

4. A. S. R. A. Dias, PhD Thesis (2019)

5. E. Damiano, L. Olivares, Nat. Hazards, 52, 2 (2010)

6. D. Mancarella, V. Simeone, Bull. Eng. Geol. Environ. 71, 4 (2012)

7. G. Sorbino, M. V. Nicotera, Eng. Geol., 165 (2013)

8. L. Picarelli, A. Evangelista, G. Rolandi, et al., 2nd Int. Workshop on Characterisation and Engineering Properties of Natural Soils (2006)

9. D. Gallipoli, S. J. Wheeler, M. Karstunen, Géotechnique, 53, 1 (2003)

10. A. Tarantino, Géotechnique, 59, 9 (2009)

11. E. Romero, J. Vaunat, Experimental evidence and theoretical approaches in unsaturated soils, CRC Press (2000)

12. R. Cardoso, G. Vecchia, C. Jommi, E. Romero, Proceedings of the 5th International Conference on Unsaturated Soils (2010)

13. D. Toll, J. Asquith, A. Fraser, et al., Asia-Pacific Conference on Unsaturated Soil, CRC Press (2015)

14. M. Th. van Genuchten, Soil Sci. Soc. Am. J. 44, 5 (1980)

15. R. Papa, M. V. Nicotera, Proc. 5th Int. Conf. Unsaturated Soils (2011)

16. S.-É. Parent, A. Cabral, J. G. Zornberg, Can. Geotech. J. 44, 10 (2007)

17. A. Azizi, G. Musso, C. Jommi, Can. Geotech. J. (2019) 